\title{
Influence of sediment characteristics on the composition of soft-sediment intertidal communities in the northern Gulf of Mexico
}

Kyle E Coblentz, Jessica R Henkel, Bryan J Sigel, Caz M Taylor

Benthic infaunal communities are important components of coastal ecosystems. Understanding the relationships between the structure of these communities and characteristics of the habitat in which they live is becoming progressively more important as coastal systems face increasing stress from anthropogenic impacts and changes in climate. To examine how sediment characteristics and infaunal community composition were related along the northern Gulf of Mexico coast, we sampled intertidal infaunal communities at seven sites covering common habitat types at a regional scale. Across 69 samples, the communities clustered into four distinct groups on the basis of faunal composition. Nearly $70 \%$ of the variation in the composition of the communities was explained by salinity, median grain size, and total organic content. Our results suggest that at a regional level coarse habitat characteristics are able to explain a large amount of the variation among sites in infaunal community structure. By examining the relationships between infaunal communities and their sedimentary habitats, we take a necessary first step that will allow the exploration of how changes in habitat and community composition influence higher trophic levels and ecosystem scale processes. 
2 Authors: Kyle E. Coblentz ${ }^{1 *}$, Jessica R. Henkel ${ }^{2}$, Bryan J. Sigel ${ }^{3}$, Caz M. Taylor ${ }^{2}$

3 Author Affiliations: 1. Department of Integrative Biology, Oregon State University, Corvallis,

4 OR, USA; 2. Department of Ecology and Evolutionary Biology, Tulane University, New

5 Orleans, LA, USA; 3. Department of Physical \& Life Sciences, Nevada State College,

6 Henderson, NV, USA; * Corresponding author; Address: 3029 Cordley Hall, Corvallis, OR

7 97331; E-mail: kyle.coblentz@science.oregonstate.edu; Phone:330-465-7987

8

9

10

11

12

13

14

15

16

17

18

19 
Coastal habitats are among the most productive and threatened on Earth and the benthic infauna, the organisms inhabiting the matrix of sediment of these habitats, are important constituents of the ecosystem. Benthic infauna are responsible for a significant amount of sediment bioturbation, secondary productivity, and nutrient cycling (Graf \& Rosenberg 1997). Therefore, cultivating an understanding of the links between benthic infauna and their habitats is an important step in working towards understanding how alteration and degradation of these habitats may influence the functioning of coastal ecosystems.

The soft-sediment intertidal habitats of the northern Gulf of Mexico coast provide a system for understanding community/habitat relationships and their implications for larger scale processes. The intertidal infaunal communities along the northern Gulf of Mexico coast are relatively understudied (but see Shelton \& Robertson 1981; Rakocinski et al. 1991; Dubois et al. 2009) despite being an important resource for many species, including threatened migratory shorebirds, a variety of fishes and economically important invertebrates (Gloeckner \& Luczkovich 2008; Henkel, Sigel \&Taylor 2012; Hsueh, McClintock \& Hopkins 1992; McTigue \& Zimmerman 1998; Quammen 1984). The habitats of these communities are experiencing unprecedented geological and anthropogenic changes. Modifications to the flow of the Mississippi River have led to drastic changes in the coastal geology of the Mississippi deltaic region and surrounding areas (Day et al. 2007), and has also resulted in the highest rates of relative sea-level rise globally (Penland \& Ramsey 1990, Zervas 2009). Moreover, in 2010 the region was affected by the Deepwater Horizon oil spill, the largest oil spill in United States

41 history (National Commission on the BP Deepwater Horizon Oil Spill and Offshore Drilling 42 2011). But understanding how infaunal communities fit into this framework of change and the 
43 potential for larger scale consequences at the ecosystem level requires a baseline understanding

44 of the relationships of communities to their habitats.

45 It has long been recognized that sediment characteristics greatly influence the structure and

46 diversity of benthic infaunal communities (Gray 1974). Relationships between sediment

47 characteristics and infaunal communities have been studied in a variety of habitats and scales.

48 Sediment grain size, organic content, food abundance, water depth, habitat structure, and salinity

49 have all been shown to influence the composition of infaunal communities (e.g. Ellingsen 2002;

50 Lindegarth \& Hoskin 2001; Mannino \& Montagna 1997; Thrush et al. 2001; Van Hoey, Degraer

51 \& Vincx 2004; Ysebaert \& Herman 2002). The relative importance of each of these factors

52 varies widely between studies, and these differences may be related to the habitat types, scale,

53 and variability of the environmental factors in the systems being examined. Therefore,

54 developing our understanding of infaunal community composition's relationship to habitat

55 characteristics in habitats for which these relationships have yet to be determined is necessary

56 before larger scale processes can be examined.

57 Here we examine invertebrate communities at seven intertidal sites along the north central

58 coast of the Gulf of Mexico representing common coastal habitat types at sites spanning a

59 regional scale. Our aim is to explore the relationships between infaunal community structure and

60 sediment characteristics to determine the environmental factors most important in structuring the

61 communities at a regional scale. We focus on the top $5 \mathrm{~cm}$. of sediment in these habitats, the

62 depth to which cores were taken by the United States Geological Survey sampling intertidal

63 invertebrates prior to landfall of the Deepwater Horizon Oil Spill in 2010 (Demopoulos \& Strom

64 2012), and the depth most likely to have the highest productivity and influence on higher trophic

65 levels (Rodil et al. 2008). 
We collected samples from seven intertidal sites along the northern Gulf of Mexico from Louisiana to Alabama (Fig. 1). Our westernmost site, CAM, was located at Broussard's Beach $\left(29^{\circ} 45^{\prime} 57.6^{\prime \prime} \mathrm{N}, 93^{\circ} 16^{\prime} 58.8^{\prime \prime} \mathrm{W}\right)$, in Cameron Parish, Louisiana. CAM is located near the mouth of the Calcasieu River, which provides freshwater input. The habitat at this site is a sandy beach composed of fine-grained sand with small fragments of shell hash. Two sites, ELMBB $\left(29^{\circ} 7^{\prime} 51.6^{\prime \prime} \mathrm{N}, 90^{\circ} 11^{\prime} 42.0^{\prime \prime} \mathrm{W}\right)$ and ELMS $\left(29^{\circ} 11^{\prime} 42.0^{\prime \prime} \mathrm{N}, 90^{\circ} 04^{\prime} 22.8^{\prime \prime} \mathrm{W}\right)$ were located on the nearshore barrier island, Elmer's Island, Louisiana. ELMBB is on the back bayside of the barrier island. The habitat is characterized by standing water, which is replenished by tidal inundation. 
layered with an algal mat that traps smaller sediment particles lying above a layer of large grained sand. Freshwater input to Dauphin Island is provided by Mobile Bay. All sites have variable salinity dependent on recent weather conditions and the amount of freshwater input provided by nearby rivers and bays.

Field and laboratory methods

We collected sediment cores from the intertidal area that is a consistently inundated under normal tidal cycles and weather conditions to determine sediment characteristics and infaunal invertebrate community composition at each site. Ten cores were collected from each site except for ELMS where one sample was lost. Samples were collected between 24 March 2012 and 6 April 2012 using a PVC corer $5 \mathrm{~cm}$ deep and $10 \mathrm{~cm}$ in diameter. The sediment collected was placed into glass jars which were kept on ice until the samples were returned to the lab. After being returned to the lab the samples were stored at $-30^{\circ} \mathrm{C}$ until processing.

In the laboratory, each sediment core was homogenized and approximately $30 \mathrm{~g}$ of sediment from each core for a given site was placed into a composite sample and was stored at $-30^{\circ} \mathrm{C}$ for later sediment analysis. The remainder of the sediment from each core was sieved through a $500 \mu \mathrm{m}$ mesh and the material remaining on the mesh was placed in a mixture of $95 \%$ ethanol for preservation and $10 \%$ Rose Bengal dye to improve sorting of invertebrates. Using a dissecting microscope, invertebrates were sorted and identified. Infaunal invertebrates were mostly identified to family except for members of Platyhelminthes and Nemertea which were identified to phylum, Bivalvia, Gastopoda and Oligocheata which were identified to class and Coleoptera which were identified to order. Invertebrates were not identified to lower levels of classification 
110 due to taxonomic uncertainties and to avoid complications arising from using disparate levels of

111 classification.

112 The composite sediment samples were analyzed for total organic content (TOC), pore water 113 salinity, median grain size and the grain size coefficient of variation. TOC was determined for 114 each site by first drying approximately three grams of sediment in a muffle oven at $60^{\circ} \mathrm{C}$ for 14 115 hours and then burning the sample at $450^{\circ} \mathrm{C}$ for six hours; TOC was calculated as the percent 116 weight lost between the dry and burned sediment. To obtain pore water salinity, pore water was 117 extracted from the sediment in the lab and salinity was measured using a salinity refractometer. 118 Median grain size and grain size coefficient of variation were measured using an LS 13320 119 Laser Diffraction Particle Size Analyzer. Details on the methods used for obtaining the grain size distribution using laser diffraction can be found in Coblentz et al. (2014).

Abundance of invertebrates (individuals of each taxon $/ 0.08 \mathrm{~m}^{2}$ ) was calculated after pooling the 10 sub-samples per site, excepting ELMS where 9 samples were pooled $\left(0.071 \mathrm{~m}^{2}\right)$. For each site, taxa accumulation curves were plotted and visually assessed to ensure that each community had been adequately sampled (Fig. 2). To examine the relationships between environmental variables and invertebrate community composition, the matrix of square root transformed taxa

127 abundances for all sub-samples was used with non-metric multidimensional scaling (NMDS;

128 Clarke \& Warwick 2001) using the Bray-Curtis dissimilarity index to group sites according to community composition. The ordination results were plotted and examined for any clear 130 groupings among sites. Analysis of similarity (ANOSIM) was applied post hoc to test for 131 significant differences between hypothesized groupings. To analyze the relationships between 
132 community composition and sediment characteristics, the bioenv function was used in the $\mathrm{R}$

133 package vegan (Oksanen et al. 2011, vegan, v. 2.0-2). This function provides the subset of

134 variables that has the highest Spearman Rank Correlation Coefficient with the Bray-Curtis

135 dissimilarity index (Clarke \& Ainsworth 1993). For each of the variables selected by the bioenv

136 function, a smooth surface representing the environmental variable was overlaid onto the NMDS

137 using the ordisurf function in the R package vegan (Oksanen et al. 2011, vegan, v. 2.0-2). This

138 procedure develops a visual representation of the relationships between community composition

139 and sediment characteristics. All statistics were performed in R (v2.14.2; R Development

140 CoreTeam 2012).

Invertebrates representing five phyla, seven classes, and fifteen families were identified across the 69 sediment cores (Table 1). The invertebrate communities from our seven sites were clustered into four distinct groupings (Fig. 3A; stress =0.04; ANOSIM, R=0.9989, p=0.001).

145 Our only remnant wetland site, OS, was a unique community and was dominated by tubebuilding tanaid crustaceans, but had high taxonomic richness including four families of 147 polychaetes, three families of amphipods, and bivalves. 83.6\% of the abundance consisted of tanaids, followed by $12.5 \%$ corophiid amphipods, and $3 \%$ polychaetes. The remainder was composed of gammarid and ischyocerid amphipods, the isopod family Idoteidae, and bivalves. The sandy beach habitat at DIS was also a unique community and was dominated by interstitial 151 oligochaetes and nemerteans, with a low abundance of interstitial platyhelminths. The two back152 bay pool sites, DIP and ELMBB, formed a cluster due to similar communities dominated by 153 ephydrid fly larvae, which composed $92 \%$ of the abundance at ELMBB and $66.5 \%$ of the 154 abundance at DIP. The remainder of the abundance at ELMBB consisted of insect larvae adapted 
155 to salt marsh conditions. At DIP, $20.2 \%$ of the remaining abundance was composed of insect

156 larvae adapted to salt marsh conditions and $13.2 \%$ of the abundance was composed of capitellid

157 polychaetes and oligochaetes. The three remaining ocean-side beach sites, CAM, ELMS, and

158 WAVE, also formed a cluster and had similar communities dominated by haustoriid amphipods

$159(96.5,97.4$, and $97.2 \%$ of the abundance respectively) with a small number of bivalves.

160 The model of environmental characteristics with the highest Spearman Rank Correlation to

161 the dissimilarity matrix included a combination of salinity, median grain size and organic content

162 (bioenv, $\rho=0.67$, Fig. 3A, Fig. 4). Salinity was highest in the pool habitats, DIP and ELMBB,

163 and was well over the salinity of seawater, while salinity at the other sites ranged from 14 to 5

164 (Fig. 3B,Fig. 4). Sediment median grain size was highest at DIS and lowest at OS, although OS

165 had a high coefficient of variation in grain size (Fig. 3C, Fig. 4). TOC was highest at OS and was

166 lower at all other sites, and was particularly low at DIS (Fig. 3D,Fig. 4).

\section{Discussion}

Previous studies have related benthic invertebrate community structure to several habitat characteristics with a relatively wide range in the explanatory power of the environmental variables measured (e.g. Ellingsen 2002; Lindegarth \& Hoskin 2001; Mannino \& Montagna 1997; Thrush et al. 2001; Van Hoey, Degraer, \& Vincx 2004; Ysebaert \& Herman 2002). Here

172 we examined intertidal macrobenthic communities at sites covering common habitat types across

173 a broad geographic region. The communities clustered into four distinct groups, although local

174 variation in abundances of community members was evident. Nevertheless, nearly $70 \%$ of

175 variation in the communities between sites was explained by salinity, median grain size, and 176 organic content. 

characteristics, which are reflected quantitatively by the sediment characteristics measured. For example, the two pool sites, ELMBB and DIP, clustered together in community composition due to dominance of salt-tolerant insect larvae. This result is not surprising due to high pore-water salinity measurements in both of the pool habitats, likely from the evaporation of water in the pools. Similarly, presence of the roots of dead vegetation at the remnant wetland site OS provides a unique habitat characteristic among the sites we examined. In turn this habitat characteristic is reflected in the high TOC measurements from the sediment cores at OS. Hence, the three sediment variables included in the model for explaining variation in community composition across sites appear to provide a good quantitative description of the coarse habitat characteristics leading to differences between sites. Similar results have been found in other studies where general sediment characteristics, such as percent mud or silt-clay, explain a large component of the variation in infaunal community composition (Ellingsen 2002; Ysebaert \& 190 Herman 2002).

Sediment grain size coefficient of variation was measured, but was not included in the model explaining the largest amount of variation in community composition. However, in another study we showed that sediment grain size coefficient of variation was a significant explanatory factor in the taxonomic richness of these communities (Coblentz et al. 2014). This suggests that the variables related to community composition at the regional scale we examined may not be the same as those that are related to diversity in the same communities. In fact, Shannon's diversity was low across all sites and was not associated with any of the environmental variables measured. DIP had the highest evenness of the sites examined, while the remaining sites were dominated by one or a few taxa contributing to relatively low Shannon's diversity values (Figure 
200

201

202

203

204

205

206

207

208

209

210

211

212

213

214

215

216

217

218

219

220

221

222

4). The dominance of one or a few taxa in benthic intertidal habitats has been observed in similar studies and provides an explanation for the low Shannon's diversity values and the variability observed across communities (e.g. Shelton \& Robertson 1981, Ysebaert and Herman 2002).

Despite the geographic distances among sites, our data show that sediment characteristics are still able to explain a differences in invertebrate community structure among habitat types. This result is promising for the management of coastal habitats and ecosystems along the northern the Gulf of Mexico. Our results suggest that, rather than needing detailed information on a variety of different environmental variables, knowledge of a few general habitat characteristics is sufficient to predict the "type" of invertebrate community present in a given habitat. The association of community composition to habitat characteristics facilitates a predictive framework of how communities might respond to both natural and anthropogenic changes in habitat characteristics. Although it is unlikely that infaunal invertebrates will be managed directly, their trophic link to ecologically and economically important shorebirds, fishes and invertebrates makes the knowledge of infaunal invertebrate habitat associations an important endeavor (Gloeckner \& Luczkovich 2008; Henkel, Sigel \& Taylor 2012, Hsueh, McClintock \& Hopkins 1992, McTigue \& Zimmerman 1998, Quammen 1984).

As coastal ecosystems continue to face pressures due to global climate change and anthropogenic impacts, understanding how communities of organisms are associated with components of their habitats is important to predict and understand how ongoing and future changes are likely to shape the functioning and composition of coastal ecosystems. Here we establish a baseline for this goal in the northern Gulf of Mexico by examining the relationships between infaunal invertebrate communities and the sediment in which they live. To build on this baseline, we suggest that further research examine the ecosystem functions provided by the 
223 infauna in different habitat types such as secondary production, bioturbation and nutrient cycling

224 and how these functions are likely to change in response to predicted changes in coastal

225 gemorphology and land use. Research along these lines will help us to understand how future

226 changes will not only affect communities of infaunal invertebrates, but, through their ecosystem

227 functions, their impact on higher trophic levels and the coastal ecosystem as a whole.

Acknowledgements

229

230

231

232

233

234

235

236

237

238

239

240

241

242

243

We thank Dr. Alex Kolker for use of his laboratory to analyze sediment granulometrics, Alex Ameen for assistance in sediment analysis, Kelly Platt and Sarah Romeo for assistance in sorting invertebrates, and other members of CazLab (caz.tulane.edu) for helpful discussion.

\section{References}

Clarke KR, Warwick RM. 2001. Change in marine communities: an approach to statistical analysis and interpretation, 2nd edition. PRIMER-E, Plymouth, UK.

Clarke K R, Ainsworth, M. 1993. A method of linking multivariate community structure to environmental variables. Marine Ecology Progress Series. 92: 205-219.

Coblentz KE, Henkel JR, Sigel BJ, Taylor CM. 2014. Technical Note: The Use of Laser Diffraction Particle Size Analyzers for Inference on Infauna-Sediment Relationships. Estuaries and Coasts. 38:699-702.

Day Jr. JW, Boesch DF, Clairain EJ, Kemp GP, Laska SB, Mitsch WJ, Orth K, Mashriqui H, Reed DJ, Shabman L, Simenstad CA, Streever BJ, Twilley RR, Watson CC, Wells JT, Whigham DF. 1997. Restoration of the Mississippi delta: Lessons from Hurricanes Katrina and Rita.

Science. 315:1679-1684. 
244 Demopoulos AWJ, Strom DJ. 2012. Benthic community structure and composition in sediment

245 from the northern Gulf of Mexico shoreline, Texas to Florida. U.S. Geological Survey Open-File 246 Report 2012-1153. 15 p. (also available at http://pubs.usgs.gov/of/2012/1153/).

247 Dubois S, Gelpi CG, Condrey RE, Grippo MA, Fleeger JW. 2009. Diversity and composition of 248 macrobenthic community associated with sandy shoals of the Louisiana continental shelf.

249 Biodiversity and Conservation. 18: 3759-3784.

250 Ellingsen KE. 2002. Soft-sediment benthic biodiversity on the continental shelf in relation to 251 environmental variability. Marine Ecology Progress Series. 232:15-27.

252 Gloeckner DR, Luczkovich JJ. 2008. Experimental assessment of trophic impacts from a 253 network model of a seagrass ecosystem: direct and indirect effects of gulf flounder, spot and 254 pinfish on benthic polychaetes. Journal of Experimental Marine Biology and Ecology. 357:109255120.

256 Graf G, Rosenberg R. 1997. Bioresuspension and biodeposition: a review. Journal of Marine 257 Systems. 11:269-278.

258 Gray JS. 1974. Animal-sediment relationships. Oceanography and Marine Biology: an Annual 259 Review. 12: 223-261.

260 Henkel JR, Sigel BJ, Taylor CM. 2012. Global impacts of the Deepwater Horizon oil spill: Can 261 local disturbance affect distant ecosystems through migratory shorebirds? BioScience. 62:676262685. 
263 Hsueh PW, McClintock JB, Hopkins TS. 1992. Comparative study of the diets of the blue crabs

264 Callinectes similis and C. sapidus from a mud-bottom habitat in Mobile Bay, Alabama. Journal 265 of Crustacean Biology. 12:615-619.

266 Lindegarth M, Hoskin M. 2001. Patterns of Macro-fauna in different types of estuarine, soft 267 sediment habitats adjactent to urban and non-urban areas. Estuarine, Coastal and Shelf Science. $268 \quad 52: 237-247$.

269 Maninno A, Montagna PA. 1997. Small-scale spatial variation of macrobenthic community 270 structure. Estuaries and Coasts. 20: 159-173.

271 McTigue TA, Zimmerman RJ. 1998. The use of infauna by juvenile Penaeus aztecus (Ives) and 272 Penaeus setiferus (Linnaeus). Estuaries. 21:160-175.

273 National Commission on the BP Deepwater Horizon Oil Spill and Offshore Drilling. Deep 274 Water: The Gulf Oil Disaster and the Future of Offshore Drilling. Washington: Government 275 Printing Office. 2011.

276 Oksanen JF, Blanchet G, Kindt R, Legendre P, Minchin PR, O'Hara RB, Simpson GL, Solymos

277 P, Henry M, Stevens H, Wagner H. 2011. vegan: Community Ecology Package. R package

278 version 2.0-2. http://CRAN.R-project.org/package=vegan

279 Penland S, Ramsey KE. 1990. Relative sea-level rise in Louisiana and the Gulf of Mexico: 1908280 1988. Journal of Coastal Research. 6:323-342.

281 Quammen ML. 1984. Predation by shorebirds, fish, and crabs on invertebrates in intertidal 282 mudflats: an experimental test. Ecology. 65:529-537. 
283 R Development Core Team. 2012. R: A language and environment for statistical computing. R

284 Foundation for Statistical Computing, Vienna, Austria.

285 Rakocinski C, Heard RW, Simons T, Gledhill D. 1991. Macroinvertebrate Associations from

286 Beaches of Selected Barrier Islands in the Northern Gulf of Mexico: Important Environmental

287 Relationships. Bulletin of Marine Science. 48: 689-701.

288 Rodil IF, Cividanes S, Lastra M, López J. 2007. Seasonal variability in the vertical distribution

289 of benthic macrofauna and sedimentary organic matter in an estuarine beach (NW Spain).

290 Estuaries and Coasts. 31:382-395.

291 Shelton CR, Robertson PB. 1981. Community structure of intertidal macrofauna on two surf-

292 exposed Texas sandy beaches. Bulletin of Marine Science. 31:833-842.

293 Thrush SF, Hewitt JE, Funnell GA, Cummings VJ, Ellis J, Schultz D, Talley D, Norkko A. 2001.

294 Fishing disturbance and marine biodiversity: the role of habitat structure in simple soft-sediment 295 systems. Marine Ecology Progress Series. 223:277-286.

296 Van Hoey G, Degraer S, Vincx M. 2004. Macrobenthic community structure of soft-bottom 297 sediments at the Belgian Continental Shelf. Estuarine, Coastal and Shelf Science. 59: 599-613.

298 Ysebaert TJ, Herman PMJ. 2002. Spatial and temporal variation in benthic macrofauna and 299 relationships with environmental variables in an estuarine, intertidal soft-sediment environment. 300 Marine Ecology Progress Series. 244: 105-12.

301 Zervas, C. 2009. Sea Level Variations of the United States 1854-2006. NOAA Technical report

302 NOS CO-OPS 53, 194p. <http://tidesandcurrents.noaa.gov/publications/Tech_rpt_53.pdf $>$ (27

303 April 2015). 


\section{Table $\mathbf{1}$ (on next page)}

Community composition of infaunal invertebrates.

Invertebrate abundance per $0.08 \mathrm{~m}^{2}$ except ELMS where abundance per $0.071 \mathrm{~m}^{2}$ is reported. 


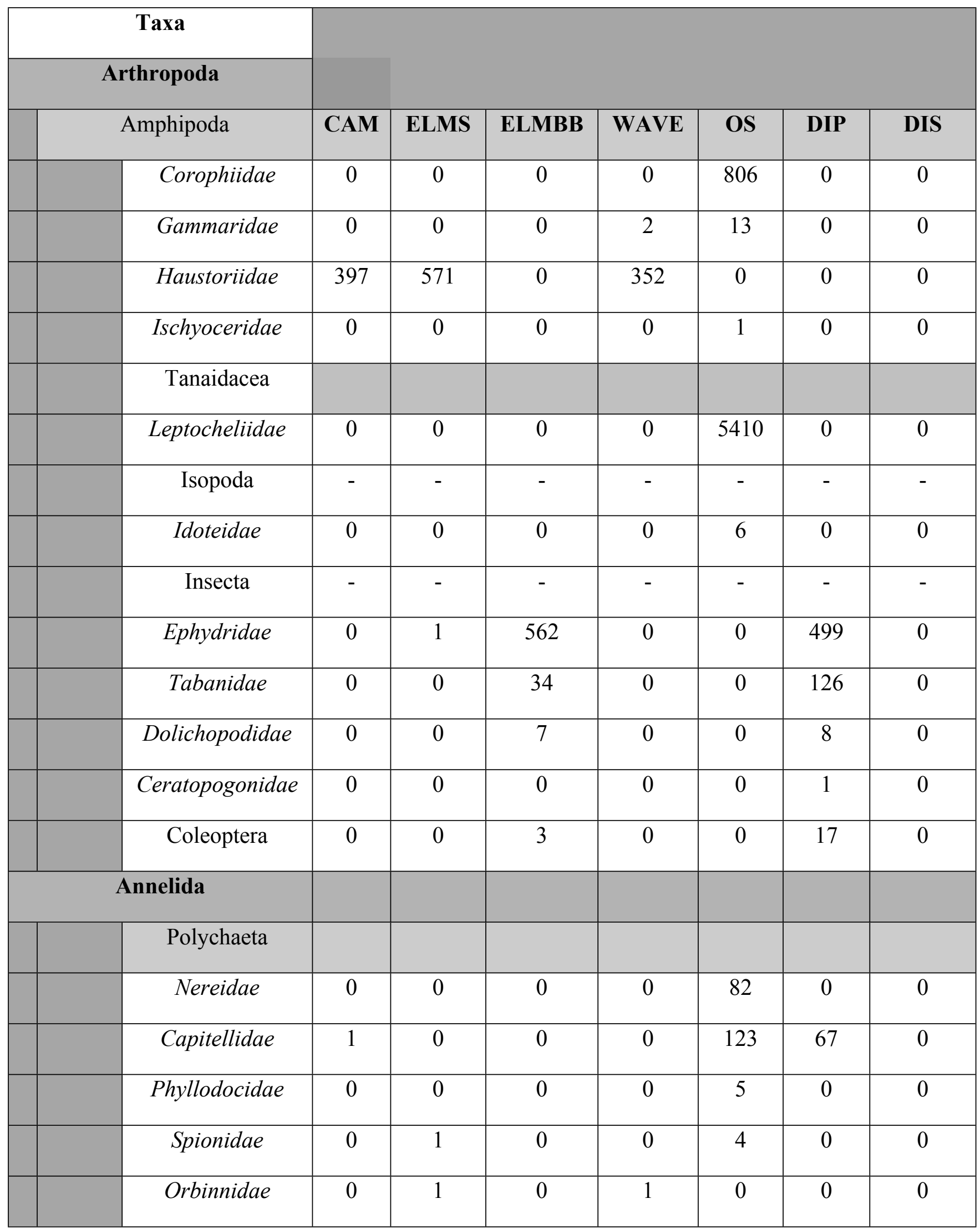




\begin{tabular}{|l|c|c|c|c|c|c|c|c|}
\hline \multicolumn{2}{|c|}{ Oligochaeta } & 0 & 0 & 0 & 0 & 0 & 32 & 644 \\
\hline \multicolumn{2}{|c|}{ Nemertea } & 0 & 0 & 0 & 0 & 0 & 0 & 74 \\
\hline \multicolumn{2}{|c|}{$\begin{array}{l}\text { Platyhelminthes } \\
\text { Mollusca }\end{array}$} & 0 & 0 & 0 & 0 & 0 & 0 & 6 \\
\hline & Bivalvia & 13 & 12 & 0 & 4 & 17 & 0 & 0 \\
\hline & Gastropoda & 0 & 0 & 0 & 3 & 0 & 0 & 0 \\
\hline & TOTAL & 411 & 586 & 606 & 362 & 6467 & 750 & 724 \\
\hline
\end{tabular}


1

Map of Northern Gulf of Mexico Coast

Map of the sampling sites. 

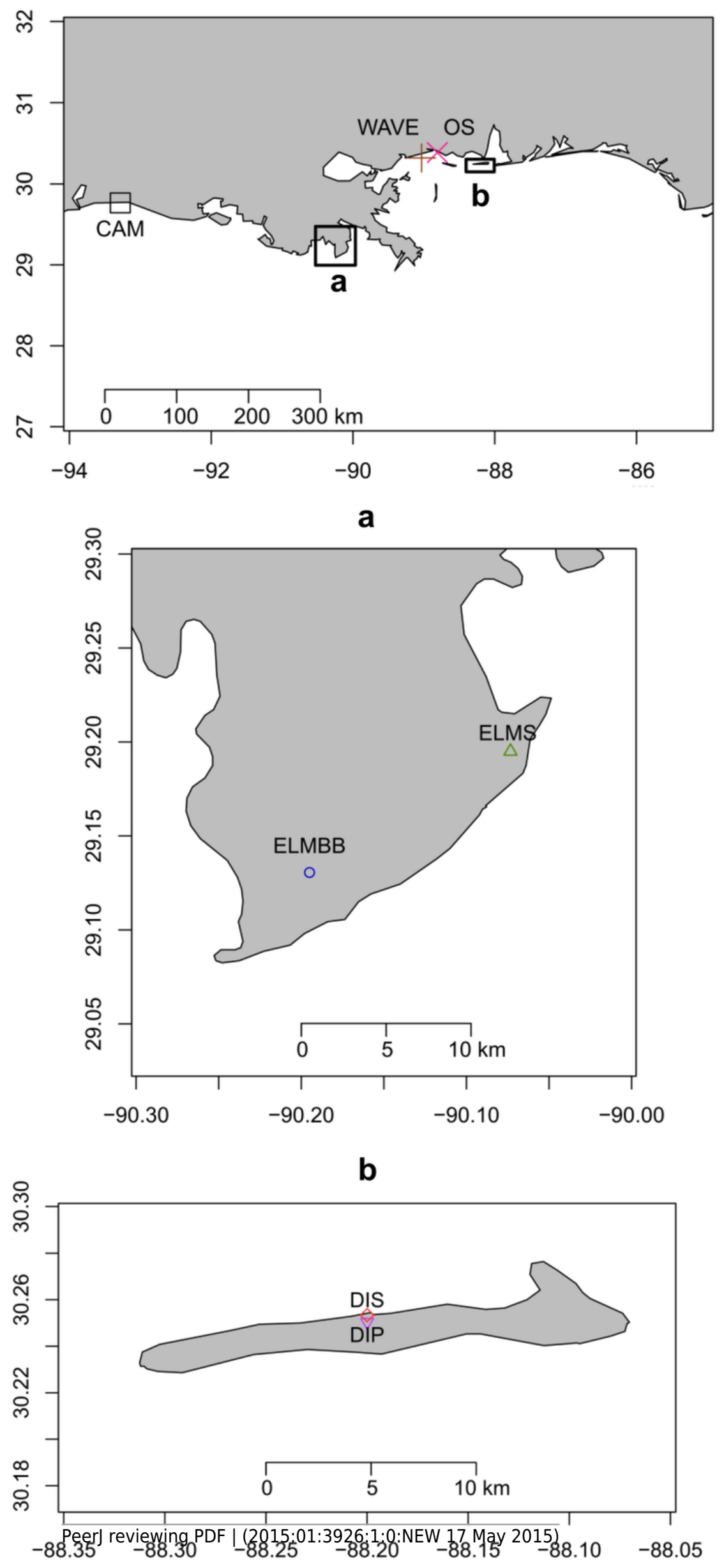
2

Taxa accumulation curves

Taxa accumulation curves for the seven sampling sites.

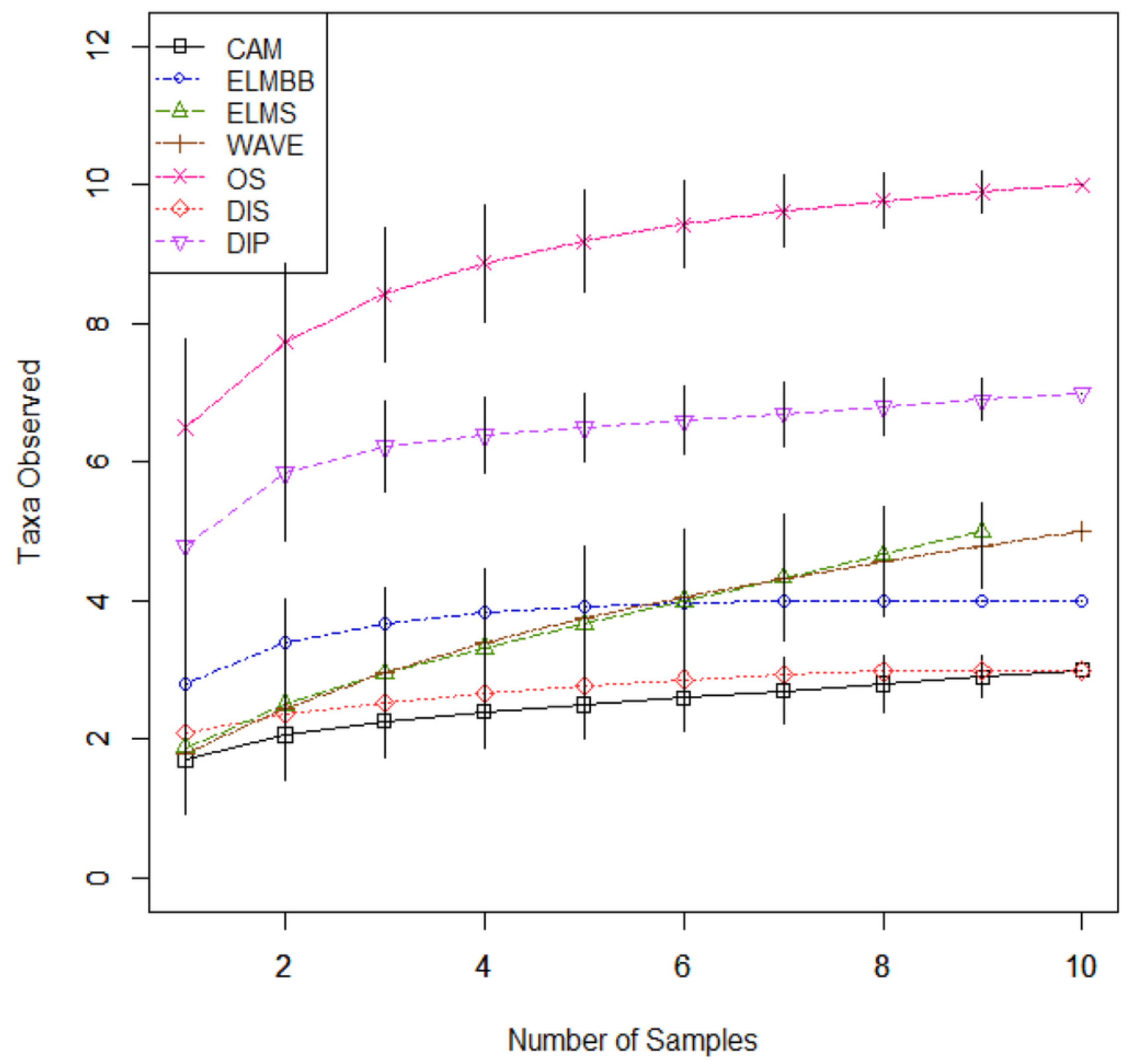




\section{3}

Community composition across sites.

A) An NMDS (non-metric multidimensional scaling) plot of sub-samples of intertidal infaunal invertebrate macrofauna collected from seven sites across the northern Gulf of Mexico (stress $=0.04$ ). The samples comprise four distinct communities (DIS; OS;

ELMS+WAVE+CAM; ELMBB+DIP; ANOSIM, $R=0.9989, p=0.001$ ). Ellipses represent $99 \%$ confidence intervals on the centroids of sites. B) NMDS plot of sub-samples with a smooth response surface of salinity values overlaid on the NMDS obtained by the function ordisurf in the vegan package (Oksanen et al. 2011, vegan, v. 2.0-2). C) NMDS plot of sub-samples with a smooth response surface of median grain size values overlaid. D) NMDS plot of subsamples with a smooth response surface of total organic content values is overlaid. 
a
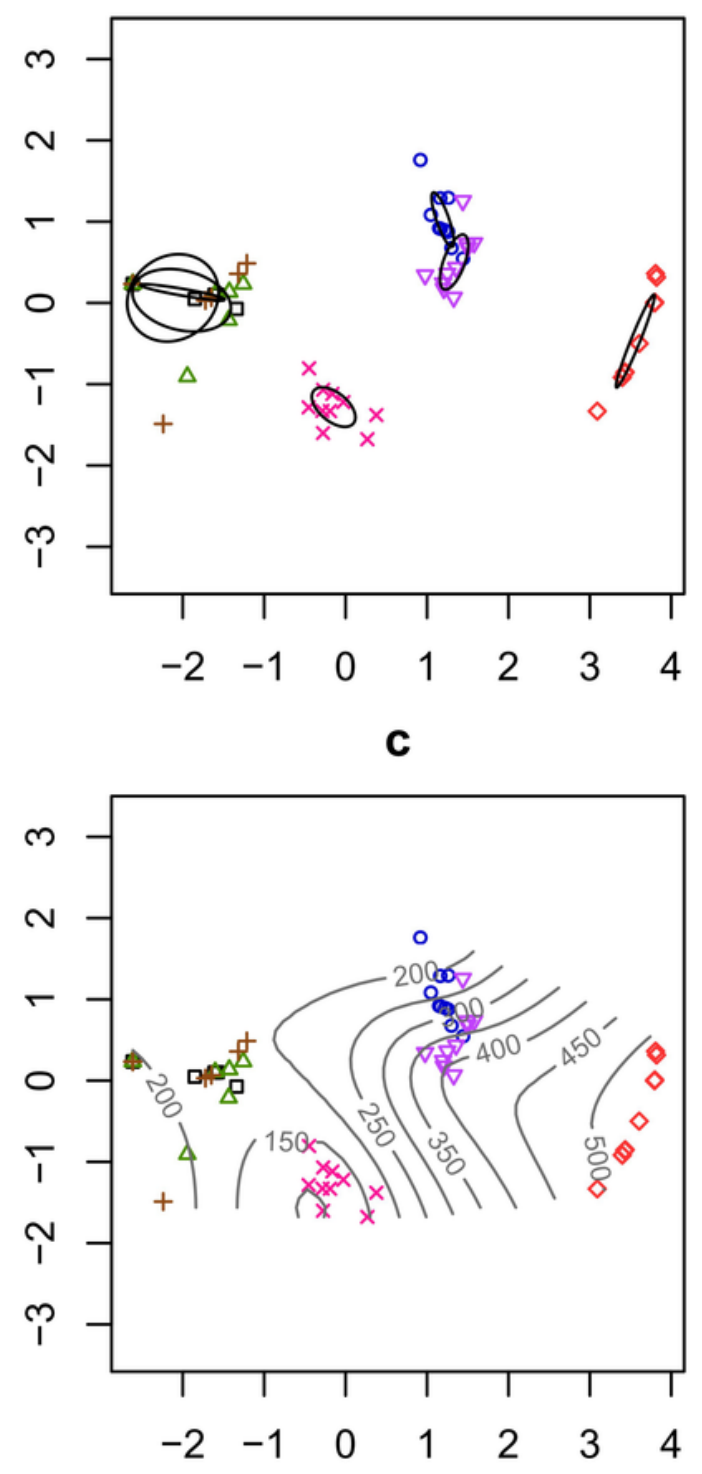

b
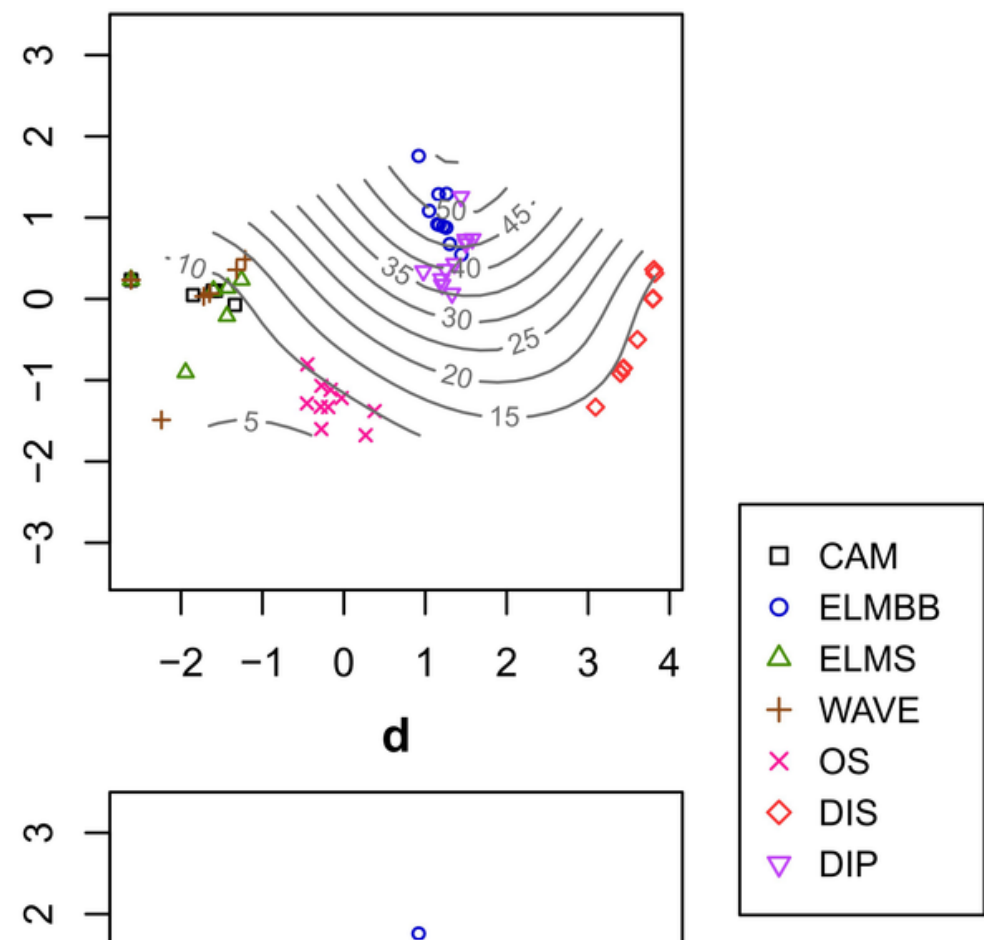
4

Summary Figure

Summary of environmental variables, richness and Shannon's diversity measured at each site. A table with exact values can be found in the Supplementary Material.
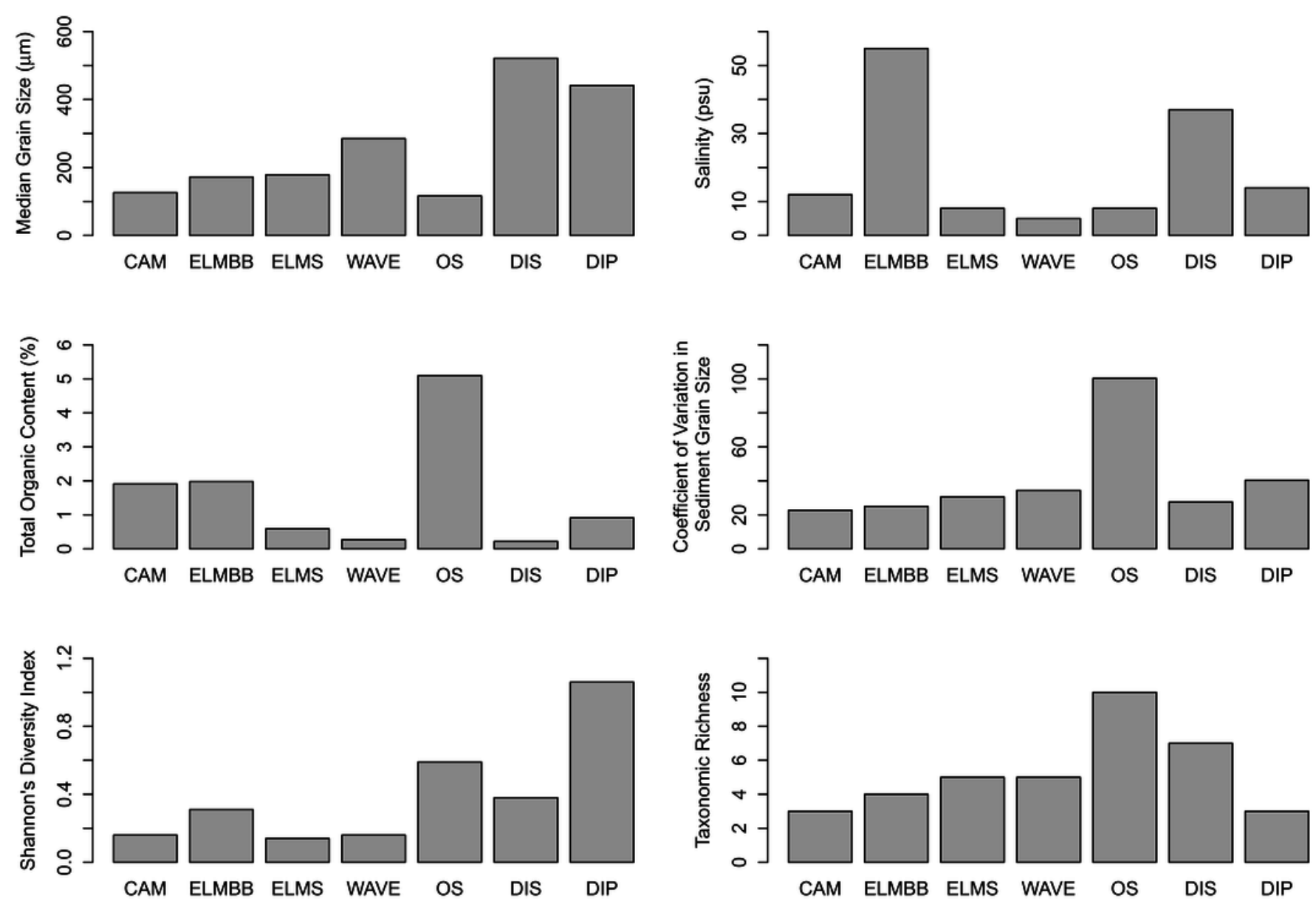